\title{
Physical-chemical Properties and in vitro Biocompatibility Assessment of Spider Silk, Collagen and Polyurethane Nanofiber Scaffolds for Vascular Tissue Engineering
}

\author{
Chuanglong $\mathrm{He}^{1,2^{*}}$, Lei Zhang², Hongsheng Wang ${ }^{2}$, Fan Zhang ${ }^{2}$, Xiumei $\mathrm{Mo}^{1,2}$ \\ ${ }^{1}$ State Key Laboratory for Modification of Chemical Fibers and Polymer Materials, Donghua University, Shanghai, 2016204 \\ ${ }^{2}$ College of Chemistry and Chemical Engineering and Biological Engineering, Donghua University, Shanghai, 201620 \\ *Corresponding authors. Email: hcl@dhu.edu.cn
}

\begin{abstract}
In this study, three kinds of nanofiber scaffolds including spider silks (SS), collagen, and polyurethane (PU) were fabricated by electrospinning technique. Their physical-chemical properties such as surface hydrophilicity, water stability, and porosity were investigated by water contact angle (CA) measurement, stabilization assay and scanning electron microscope (SEM). Results showed that SS scaffolds had stronger hydrophobic surface, superior water-stability and higher porosity than other scaffolds. Furthermore, their in vitro biocompatibility including cell attachment, spreading, and proliferation were evaluated and compared by using porcine aorta endothelium cells (PIECs). The MTT results showed that the cell proliferation on SS nanofibers was significantly higher than that on collagen and PU scaffoldss, the SEM images demonstrated that the PIECs can migrate into SS nanofibers and maintain a spreading shape, and the RT-PCR results also indicated the SS nanofiber scaffolds promote better cell growth and proliferation. Thus, these results strongly suggest the potential application of SS nanofibers as vascular engineering scaffolds.
\end{abstract}

Keywords: Spider silk; In Vitro Biocompatibility; Electrospinning; Nanofibers; Vascular tissue engineering

Citation: C. He, et al. Physical-chemical properties and in vitro biocompatibility assessment of spider silk, collagen and polyurethane nanofiber scaffolds for vascular tissue engineering. Nano Biomed Eng. 2009, 1(1), 80-88. DOI: 10.5101/nbe.v1i1.p80-88

\section{Introduction}

Vascular tissue engineering has emerged as one of the most promising approaches to developing ideal vascular substitutes with properties similar to that of native tissue [1-3]. In the last two decades, numerous efforts have been made to develop scaffolds for vascular tissue engineering by combining material synthesis and scaffold processing techniques. A variety of synthetic materials such as poly(caprolactone) (PCL) [4,5], poly (L-lactide) (PLA) [6], poly (glycolide) (PGA) [7] and naturally occurred materials such as collagen $[8,9]$ and fibrin [10-12] can be employed for vascular substitutes and scaffolds for vascular tissue engineering. To engineer materials mimicking the physical structure and biological function of natural blood vessel, a few technologies have been exploited with varying degrees of success [10, 11, 13-15].

Electrospinning is an attractive technique to fabricate various tissue engineering scaffolds in that it permits fabrication of scaffolds that similar to the nanofibrous structure found in the native extracellular matrix (ECM), which is mainly composed of a threedimensional network of nanofibrous proteins with fiber bundle diameter varying from 50 to $500 \mathrm{~nm}[16,17]$. Nanofibrous materials have been shown to actively regulate cellular behaviors and cell-matrix interactions because of their unique properties such as high surfaceto-volume ratio and high porosity [18]. In addition, electrospinning is able to produce aligned and oriented fiber network, which provides special benefit for 
biomimieking the hierarchical structure of natural blood vessel tissue [19]. To construct an ideal scaffold for vascular regeneration, considerable efforts have been made to create different polymeric scaffolds using electrospinning technique, focusing on the processing parameters and physical-chemical properties of materials $[14,15,19]$. However, rather less attention has been paid to compare the biocompatibility of different nanofibrous materials for vascular tissue engineering.

Spider silks (SS) have remarkable mechanical properties that make them attractive for vascular tissue engineering applications [20, 21]. The molecular structure and various characteristics of electrospun SS nanofibers have been studied widely [21, 22], little is known on their biocompatibility as tissue engineering scaffolds.

The objective of this study is to seek suitable biomaterials for vascular tissue engineering by comparing the physical-chemical properties and in vitro biocompatibility of SS, collagen and PU nanofibers. These nanofiber scaffolds were fabricated by electrospinning, the hydrophilicity, water stability, and porosity of resulting nanofiber scaffolds were tested, and their in vitro biocompatibility on Porcine Aorta Endothelium cells was assessed by cell adhesion, proliferation and expression of proliferating cell nuclear antigen (PCNA).

\section{Materials and Methods}

\subsection{Materials}

SS (Mw: 2.0-3.0 $\times 10^{5}$ ) was kindly donated by Nanning Spider Research Center (Nanning, China). Collagen (Mw: 0.8-1.0 x 10 $0^{5}$ ) was purchased from Mingrang Biotechnology CO.,LTD. (Sichuan, China). PU ( Mw: 0.5-1.0 x $10^{6}$ ) was purchased from Japan. 1,1,1,3,3,3,hexafluoro-2-propanol(HFIP) was obtained from Daikin Industries Ltd (Japan). Endothelium cells from porcine aorta (PIEC) were obtained from Institute of Biochemistry and Cell Biology (Chinese Academy of Sciences, China). Unless stated otherwise, all culture media and reagents were purchased from Gibco Life Technologies CO.

\subsection{Fabrication of nanofiber scaffolds}

SS and Collagen solution for electrospinning were prepared by dissolving SS and Collagen in HFIP at a concentration of $8 \mathrm{wt} \%$, respectively. PU was dissolved in a solvent mixture of DMF/THF (1:1 in volume) at a concentration of $20 \mathrm{wt} \%$. The solutions for electrospinning were mixed using an electromagnetic mixer until transparent and homogeneous. In the electrospinning process, the as-prepared solution was respectively loaded into a $5 \mathrm{~mL}$ plastic syringe with a stainless steel needle (inner diameter, $0.21 \mathrm{~mm}$ ) attached. The needle was connected to a high-voltage supply (BGG6-358, BMEI CO, LTD., China). The solution was fed at $0.8 \mathrm{ml} / \mathrm{h}$ using a syringe pump (789100C, Cole-Parmer Instruments Co., USA). A plate of aluminum foil was grounded and placed $13 \mathrm{~cm}$ below the needle tip, and used to collect the nanofibers. The voltage for electrospinning was set at $10-15 \mathrm{kV}$. The thicknesses of all resulting nanofibers were controlled at around $0.1 \mathrm{~mm}$. These fibers were then dried in a vacuum for $48 \mathrm{~h}$ to remove the residual solvents.

The resulting Collagen nanofibers were then crosslinked by steam of $25 \%(\mathrm{v} / \mathrm{v})$ glutaraldehyde solution for $8 \mathrm{~h}$ and dried under vacuum overnight at room temperature.

\subsection{Scaffolds characterization}

The surface hydrophilicity of nanofiber scaffolds was characterized by water contact angle (CA) measurement (OCA40, Dataphysics, Germany), and photographs were taken after distilled water dripping on them for 30 sec.

Stabilization of various nanofiber scaffolds was evaluated by immersing the scaffolds $\left(1 \mathrm{~cm}^{2}\right.$ in size) into medium under cell culture conditions for $7 \mathrm{~d}$. These nanofiber scaffolds were then washed three times with water and dried in vacuum. The weights of these nanofiber scaffolds before and after incubation with medium were measured.

The morphologies of electrospun fibers were observed with scanning electron microscope (SEM, Hitachi S-2700, Japan) at voltage of $15 \mathrm{kV}$. The diameters of the nanofibers were measured based on SEM images using image visualization software (Image J 1.34s, NIH Image, USA). The thicknesses of the nanofiber scaffolds were accurately measured with a micrometer. The apparent density and porosity of nanofiber scaffolds (NFM) were calculated according to the method reported by reference [23].

\subsection{Cell adhesion and proliferation assessment}

For biocompatibility assessment, the coverslips with 14 $\mathrm{mm}$ in diameter were placed onto the aluminum foil to collect the nanofibers scaffolds, the scaffolds were then fixed in the 24-well plate with stainless steel rings and sterilized with $75 \%$ alcohol solution, which was replaced with phosphate-buffered saline solution (PBS) after 2 hours. PIECs were cultured in a $5 \% \mathrm{CO}_{2}$, humid atmosphere at $37^{\circ} \mathrm{C}$ in DMEM medium containing $10 \%$ fetal serum, 100 units $/ \mathrm{mL}$ penicillin and 100 units $/ \mathrm{mL}$ streptomycin, the culture medium was replaced every $3 \mathrm{~d}$.

To study cell adhesion, migration, and proliferation, PIECs $\left(0.5 \times 10^{5} / \mathrm{mL}\right)$ were seeded onto nanofiber scaffolds with tissue culture plates (TCP) as control. After $6 \mathrm{~h}, 2 \mathrm{~d}$, and $5 \mathrm{~d}$ of culture, unattached cells were washed out. The cell-scaffold composites were evaluated by Hematoxylin-Eosin (HE) staining. MTT assay was also used to assess the cell proliferation ability at the absorbance of $492 \mathrm{~nm}$ by an enzyme-labeled instrument (MK3, Thermo, U.S.). 
Table 1. CA measurement of surface of nanofibers using distilled water as solvent.

\begin{tabular}{cccccc}
\hline nanofibers & $\mathbf{C A}(\mathbf{L})\left(^{\circ}\right)$ & $\mathbf{C A}(\mathbf{M})\left(^{\circ}\right)$ & $\mathbf{C A}(\mathbf{R})\left(^{\circ}\right)$ & $\mathbf{E r r}\left({ }^{\circ}\right)$ & $\mathbf{T}\left({ }^{\circ} \mathrm{C}\right)$ \\
\hline SS & 114.8 & 114.8 & 0 & 1.06 & 16.4 \\
Collagen & 63.5 & 63.5 & 0 & 1.39 & 15.5 \\
PU & 130.4 & 130.4 & 0 & 1.07 & 15.8 \\
\hline
\end{tabular}

Note: Data were representatives of three independent experiments and all data were given as means \pm SD $(n=3)$.

For further study, the morphologies of PIECs on various nanofiber scaffolds after $5 \mathrm{~d}$ of culture were observed by SEM (Hitachi S-2700, Japan). Cells cultured on scaffolds were washed with $1 \times \mathrm{PBS}$ and then fixed with $4 \%$ glutaraldehyde for $12 \mathrm{~h}$ at $4{ }^{\circ} \mathrm{C}$ The samples were dehydrated in $50 \%, 75 \%$ and $100 \%$ alcohol solutions and dried under vacuum. Afterwards, the samples were sputter coated with gold and observed with an SEM at voltage of $15 \mathrm{kV}$.

\subsection{RT-PCR detection}

PICEs on the different nanofibers were cultured for $7 \mathrm{~d}$ then trypsinized, and total RNA was extracted from the cells using QIAamp RNA mini kits (QIAGEN, USA). $5 \mu \mathrm{L}$ of RNA was reverse transcribed with MMLV reverse transcriptase (Promega, Southampton, United Kingdom) and an oligo (dT) 15 primer into cDNA which was amplified using the design primers. Heat activation, $95^{\circ} \mathrm{C}$ for 4 min, duplex amplification was performed using a thermocycler for 30 cycles according to the following program: $95{ }^{\circ} \mathrm{C}$ for $55 \mathrm{sec}, 59$ ${ }^{\circ} \mathrm{C}$ annealing for $55 \mathrm{sec}$, and $72{ }^{\circ} \mathrm{C}$ extension for $50 \mathrm{sec}$. Followed by a final extension of $72^{\circ} \mathrm{C}$ for $10 \mathrm{~min}$. PCR fragments of PCNA bands were visualized in a $1.5 \%$ agarose gel and at $100 \mathrm{~V}$ electrophoresis with $\beta$-actin (318 bp) as an internal standard. The relative intensity was then compared (Photo Image Analysis Software 7.0, SONY, Japan).

\subsection{Statistical analysis}

Statistical analysis was performed using SPSS 10.0 software for windows. All assays were repeated with a minimum of $n=3$. Statistical comparisons were based on one-way analysis of variance (ANOVA). In all evaluations, $\mathrm{p}<0.05$ was considered to be statistically significant.

\section{Results and discussion}

\subsection{Surface hydrophilicity}

Figure 1 shows the CA measurement of electrospun SS, collagen and PU nanofiber scaffolds. Collagen nanofiber scaffolds exhibited a strong hydrophilic behavior; with the angle values obtained around $60^{\circ}$ as summarized in Table 1 . The CA value of SS scaffolds was $114.8^{\circ}$, and PU nanofiber scaffolds had the highest CA value at $130.4^{\circ}$.
Generally, natural polymers which produced in aqueous environments have suitable surface for water contact. The results showed that the SS nanofiber scaffolds have less hydrophilic than collagen nanofiber scaffolds. It can be explained by the fact that SS has the unique hydrophobic amino-acid compositions and sequence, showing a predominance of glycine, alanine, and glutamine; there are also substantial amounts of leucine and tyrosine, which are among the larger amino acids [24].

\subsection{Water Stability}

Table 2 shows the results of stability of nanofiber scaffolds in culture medium after $7 \mathrm{~d}$. SS nanofiber scaffolds lost $5.55 \%$ of their weight, and collagen scaffolds lost $16.20 \%$ of their weight, respectively. PU nanofiber scaffolds showed the best stability and almost had not any weight loss after $7 \mathrm{~d}$.

It is known that collagen is polypeptide-based materials has strong hydrophilicity and low stability [25]. The results showed that SS nanofiber scaffolds in culture medium had higher stability than collagen nanofiber scaffolds. The basis for this lies in part in the amino acid sequence of silk protein, which imparts block copolymer-like behavior to the protein: hard segments form a crystalline structure that is embedded in an elastic matrix [26]. It suggests that SS nanofibers are more stable as scaffolds.

\subsection{Fiber diameter and porosity}

Nanofiber diameters were calculated from average diameter of 100 segments of fibers which were measured from SEM images as shown in Figure 2. It was found that the average diameter of SS nanofibers was $173 \mathrm{~nm}$, and the value was increase to $202 \mathrm{~nm}$ for collagen nanofibers. The average diameter of PU nanofibers (372 nm) was much greater than that of above two kinds of nanofibers as shown in Figure. 3. The highest porosity was found in the SS nanofibers which reached $65.62 \%$, however, the porosity for collagen and PU scaffolds were about $40 \%$. The change of fiber diameter and porosity among SS, collagen and PU nanofiber scaffolds could be explained by the conductivity increase of electrospun solution. The addition charged ions to polymer solutions have been found to affect fiber diameter and lead fibers substantially decrease in diameter [27]. 


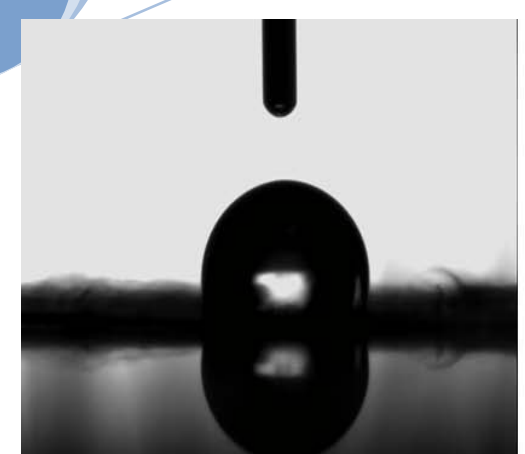

SS

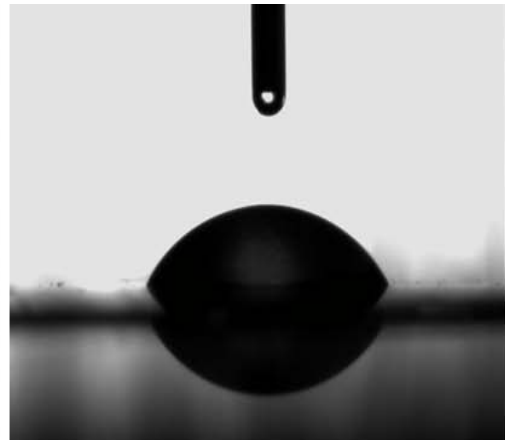

Collagen

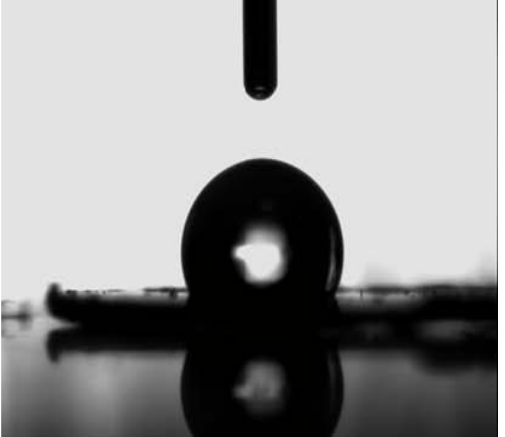

PU

Figure 1. Photographs of CA measurement of nanofiber scaffolds after distilled water dripping on them 30s later.

SS and collagen have higher polarity compared to PU, which results in the formation of salts between solvent molecules and the amino groups, the increased charges Therefore leads to a greater deposition area of electrospun fibers. In addition, the more strong hydrophobic amino acids groups in SS lead to the higher porosity.

\subsection{Cell adhesion, migration and proliferation}

The results of HE staining showed that the PIECs attached and kept normal morphology on the surface of different nanofiber scaffolds after $6 \mathrm{~h}$ of culture. After cultured for $2 \mathrm{~d}$, the number of cells on SS and collagen were higher than that on PU nanofiber scaffolds, and the number of cells on SS nanofibers was significantly higher than that on collagen and PU after $5 \mathrm{~d}$ as shown in Figure 4 suggesting that the PIECs have a rapid growth on SS nanofiber scaffolds.

Table 2. Stability of nanofiber scaffolds in cell culture medium

\begin{tabular}{ccccc}
\hline Nanofibers & $\begin{array}{c}\text { Before } \\
\text { W0 }(\times 10-2 \mathrm{~g})\end{array}$ & $\begin{array}{c}\text { After } \\
\text { W1 }(\times 10-2 \mathrm{~g})\end{array}$ & $\begin{array}{c}\text { Lost weight } \\
\text { W (\%) }\end{array}$ & Stability \\
\hline SS & $1.08 \pm 0.01$ & $1.02 \pm 0.01$ & $5.55 \%$ & + \\
Collagen & $1.15 \pm 0.02$ & $0.60 \pm 0.02$ & $47.82 \%$ & - \\
Collagen* & $1.11 \pm 0.01$ & $0.93 \pm 0.01$ & $16.20 \%$ & - \\
PU & $1.02 \pm 0.01$ & $1.00 \pm 0.01$ & $1.96 \%$ & ++ \\
\hline
\end{tabular}

Note: Data were representatives of three independent experiments and all data were given as Means \pm SD ( $n=3)$; “*” means collagen nanofibers scaffolds were crosslinked by steam of $25 \%$ (v/v) glutaraldehyde. “+” means stable; “++"means quite stable; “_”means unstable; “___"means quite unstable.

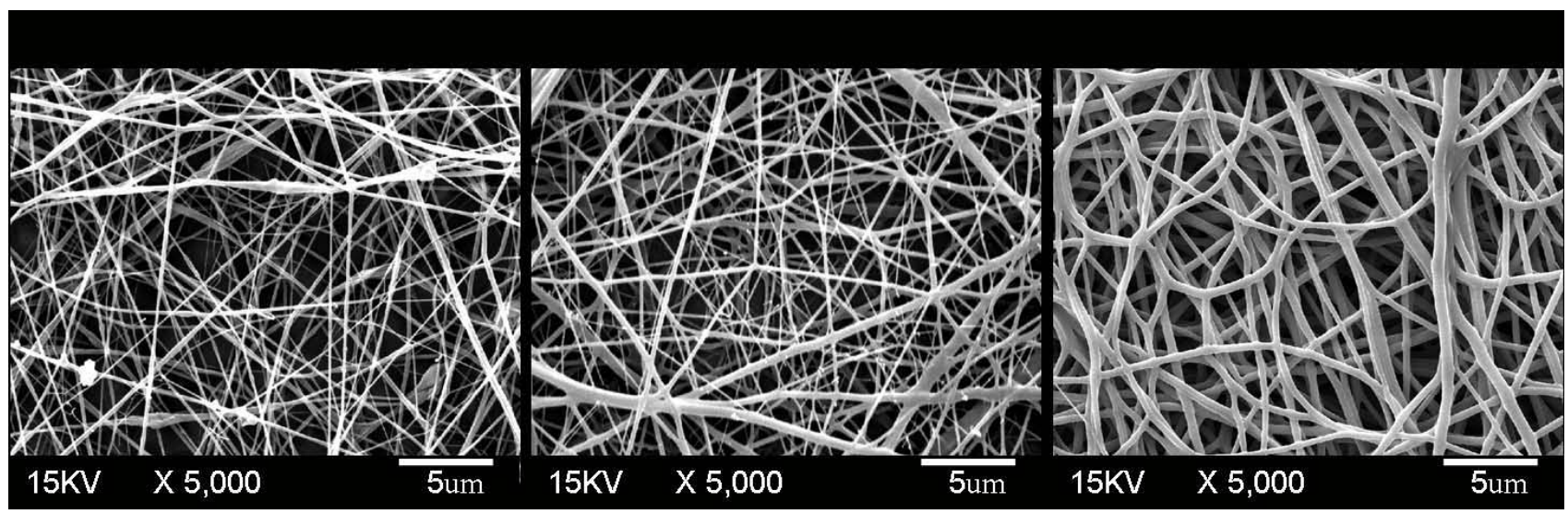

Figure 2. SEM images of electrospun SS, collagen and PU nanofiber scaffolds. 


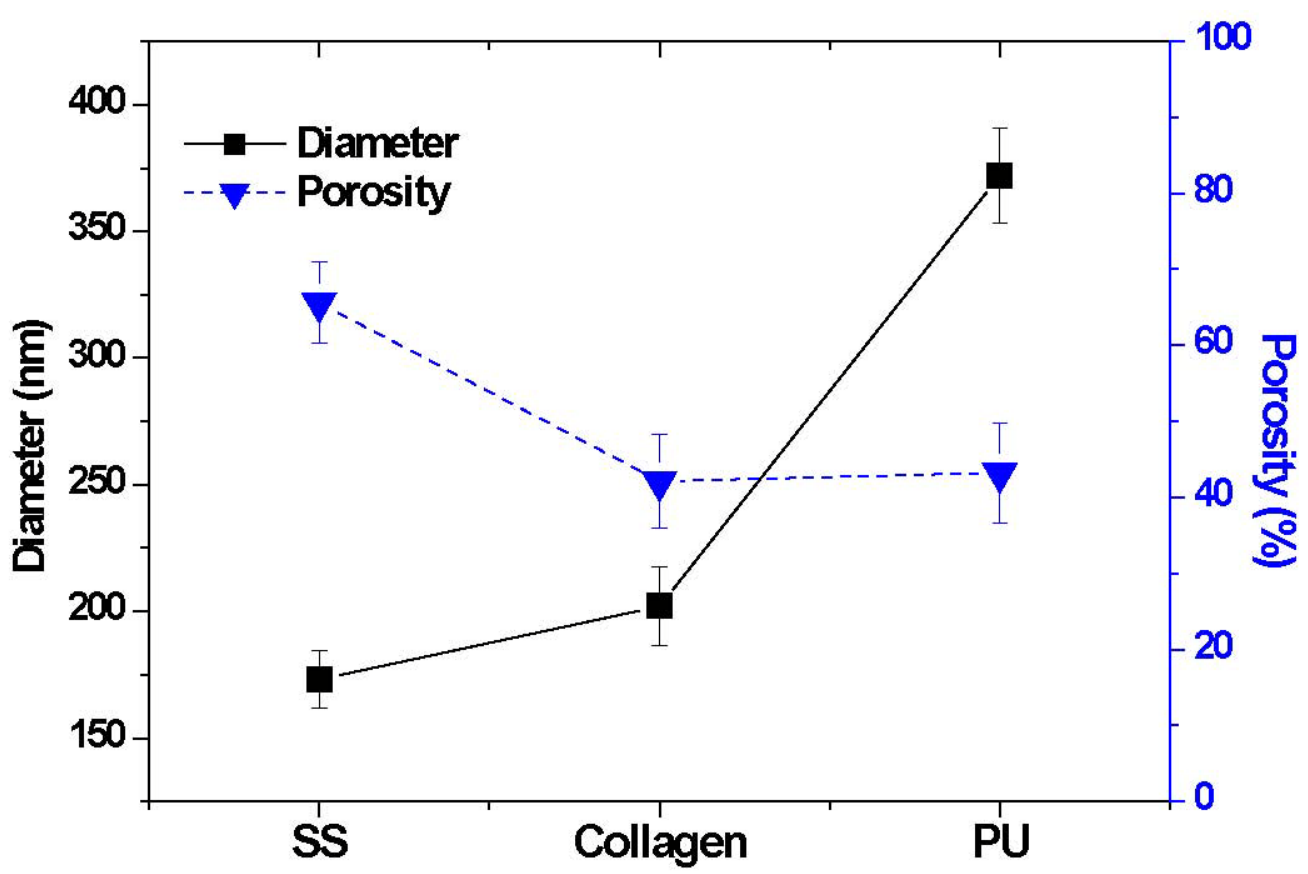

Figure 3. Average fiber diameter and porosity of SS, collagen and PU nanofiber scaffolds.

MTT assay was used to quantify the adhesion and proliferation of PIECs on different fiber scaffolds, as shown in Figure. 5. The results showed that the adhesion of cells on fiber scaffolds have no significantly difference compared with TCP for $6 \mathrm{~h}$ incubation. The MTT value for collagen nanofibers was a little higher than that for SS nanofibers after the first $2 \mathrm{~d}$, but the highest MTT value can be observed for SS nanofibers after cultured for $5 \mathrm{~d}$, which is about $20 \%$ higher than that for collagen fibers, the difference between two groups is statistically significant $(\mathrm{p}<0.05)$. That could be explained by the different water-stability between SS and collagen scaffolds. Due to the strong hydrophilicity, the structure of collagen nanofibers can be destroyed gradually in the medium after cultured for several days. Compared to collagen nanofibers, the PIECs on SS nanofibers showed higher cell proliferation. Figure 6 shows the SEM morphology and migration of PIECs on nanofiber scaffolds after $5 \mathrm{~d}$ of culture.

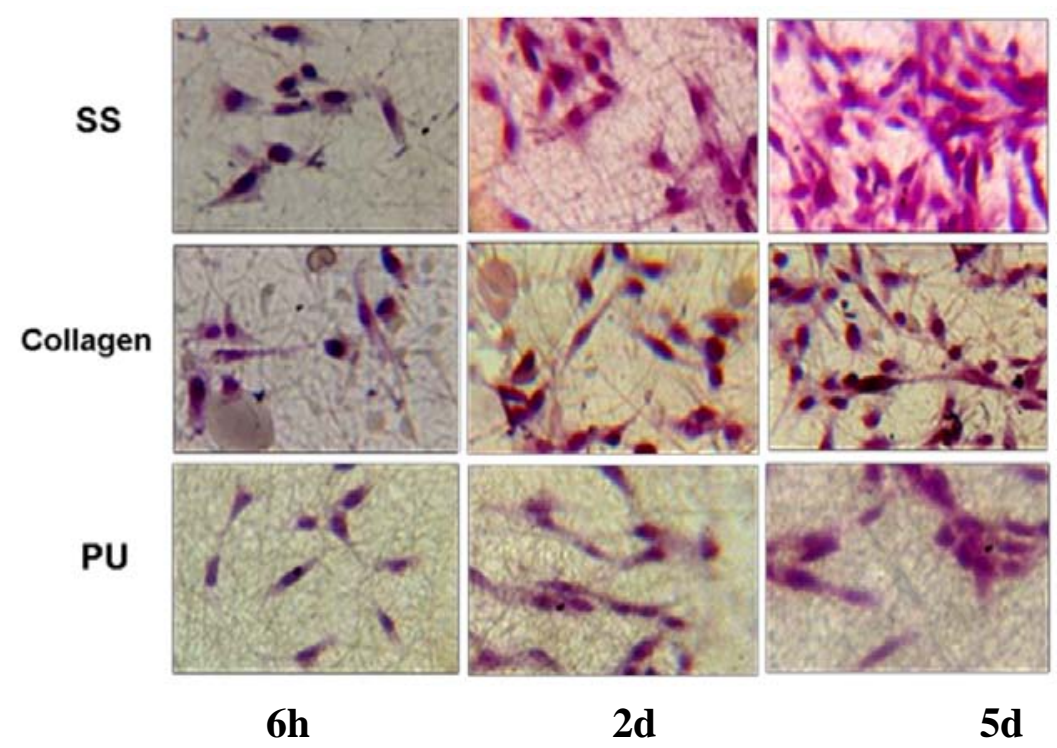

Figure 4. Hematoxylin and eosin (HE) staining images of PIECs after cultured for $6 \mathrm{~h}, 2$ days, and $5 \mathrm{~d}$. The cells were seeded equally on various nanofiber scaffolds before culture, and making sure vision of each photo was typical. 


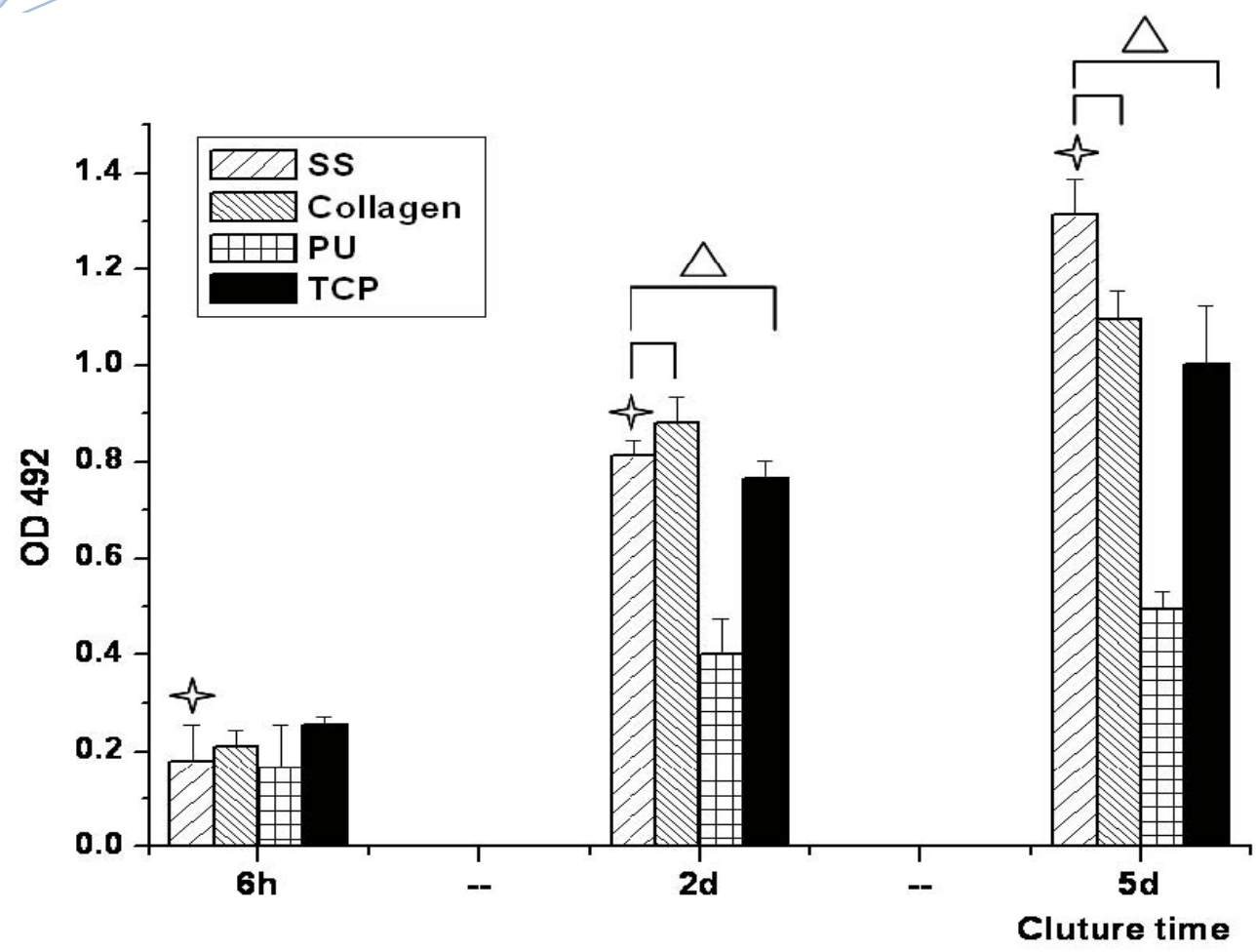

Figure 5. Adhesion and proliferation of PIECs on nanofiber scaffolds. (: SS vs Collagen and TCP, : $\mathrm{p}<0.05$; :

MTT adsorption value of SS scaffolds at $6 \mathrm{~h}, 2 \mathrm{~d}$ and $5 \mathrm{~d}, \mathrm{p}<0.01$.)

It can be observed that cells migrated into the SS and collagen nanofibers and adopted a spreading polygonal shape, indicating that these materials have good cytocompatibility, whereas for PU nanofiber scaffolds PIECs were shown to attach to fiber scaffolds but difficult to migrate into it, the cells adopted a fusiform shape instead of spreading.

\subsection{Expression of PCNA gene of PIECs}

The detection of expression of PCNA gene on molecular level was chosen to analyze the proliferation of PIECs cultured on different nanofiber scaffolds (Figure 7). The intensity relative absorption of PCNA gene, comparing with $\beta$-actin as an internal standard was shown in Figure 8. It was found the number of cells on SS nanofibers was approximately double more than that on collagen and TCP, and even four times more than that on PU after $7 \mathrm{~d}$ culture. That indicated the PIECs on SS nanofibers favored better proliferation than those on other scaffolds, and the results were in accordance with the results of HE staining and MTT assay

In vitro biocompatibility of scaffolds in vascular tissue engineering is determined by various factors. It has been reported that the polymer properties, such as chemical composition, surface hydrophobicity, surface morphology and surface energy play important roles in regulating cell growth [28]. The SS and collagen nanofibers have amino-acid side chains on their surface which greatly influences the interaction between cells and nanofibers. In addition to chemical composition, the hydrophilicty of nanofibers is another important factor influencing their biocompatibility. It was demonstrated that higher protein adsorption and protein conformational change always occurred on hydrophobic surface because proteins are difficult to deabsorb from hydrophobic surface [29]. Furthermore, the porous scaffolds with interconnected pore network are important to provide sufficient space for cell growth and tissue regeneration.

\section{Conclusions}

Three kinds of nanofiber scaffolds including SS, collagen, and PU were fabricated by electrospinning technique. These scaffolds were then evaluated and compared with each other based on vascular tissue engineering application. The results showed that SS nanofiber scaffolds possess strong surface hydrophobility, good water stability and suitable surface morphology. Furthermore, the SS nanofiber scaffolds can promote better PIECs attachment, proliferation and phenotypic morphology than collagen and PU nanofiber scaffolds. The results strongly suggest the potential application of ss nanofibers as vascular engineering scaffolds. 


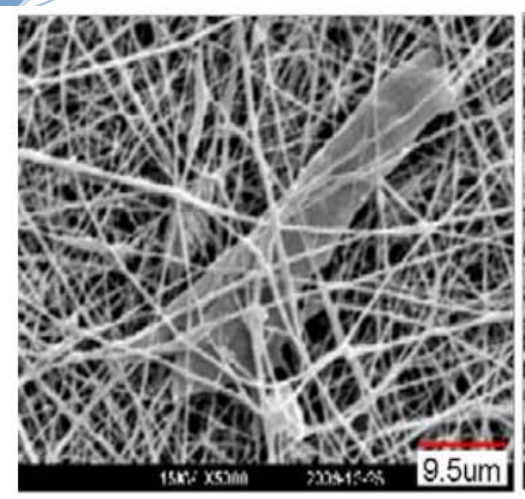

SS

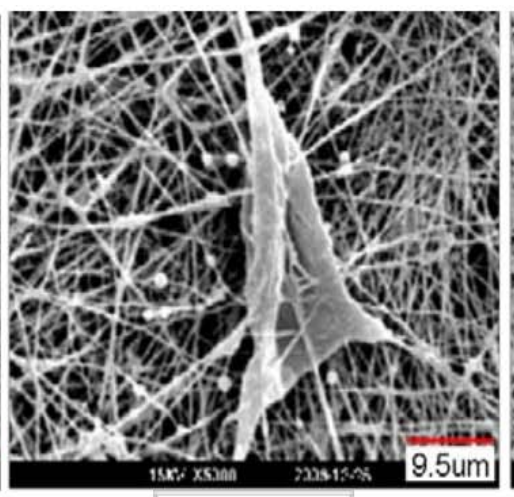

Collagen

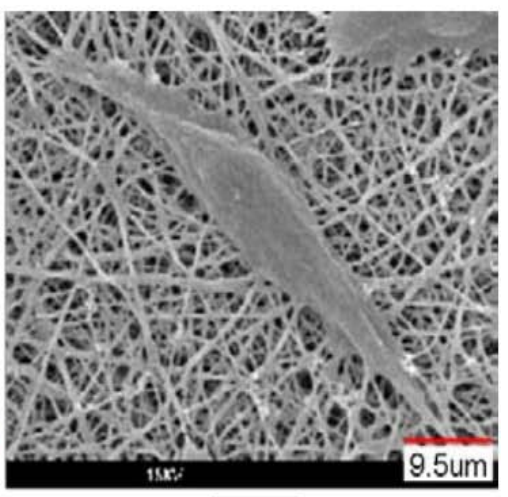

PU

Figure 6. SEM images of interaction between PIECs and nanofiber scaffolds.
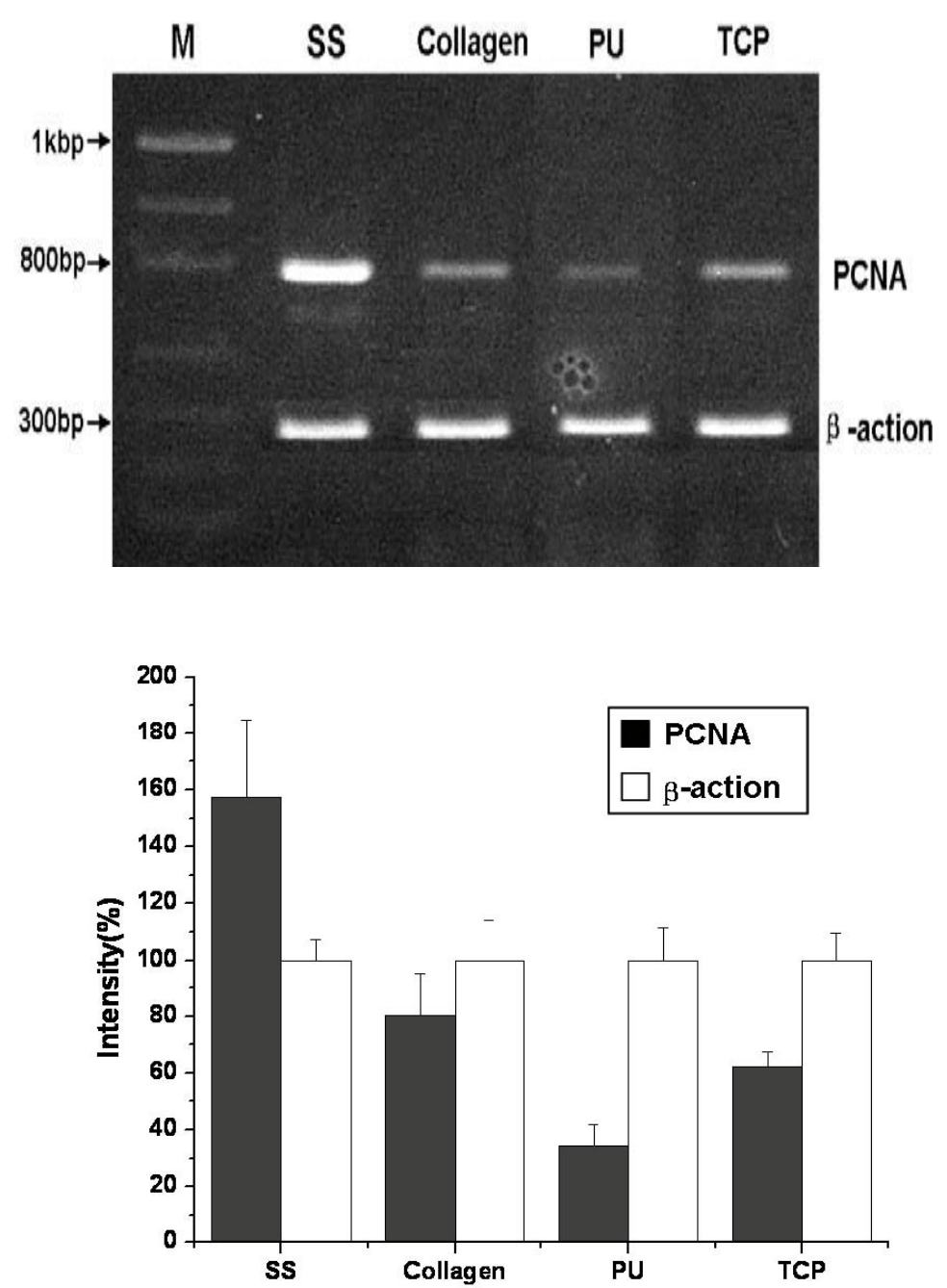

Figure 7. Expression of PCNA from PIECs cultured on nanofiber scaffolds for 7 days, and $\beta$-actin as an internal standard. The PCR primers designed as sense PCNA (5'-CTC CTT CCC GCC TGC CTG TA-3'), antisense PCNA (5'-AAT GCC TAA GAT CCT TCT TCA TCC-3'), sense $\beta$-actin (5'-ATC ATG TTT GAG ACC TTC AAC A-3') and antisense $\beta$-actin (5'-CAT CTC TTG CTC GAA GTC CA-3'). Histograms showed fluorescence intensity of bands expressed as a percentage of the intensity of $\beta$-actin. 


\section{Acknowledgements}

This work was supported by the National High Technology Research and Development Program of China (2008AA03Z305), Natural Science Foundation of Shanghai (07ZR14001), Doctoral Fund of Ministry of Education of China (200802551014), Open Foundation of State Key Laboratory for Modification of Chemical Fibers and Polymer Materials, and the Program of Introducing Talents of Discipline to Universities (B07024).

\section{References}

1. Grenier S, Sandig M, Mequanint K. Polyurethane biomaterials for fabricating 3D porous scaffolds and supporting vascular cells. J Biomed Mater Res 2007; 82 A: 802-9.

2. Arrigoni C, Camozzi D, Remuzzi A. Vascular tissue engineering. Cell Transplant 2006; 15: S119S25. doi:10.3727/000000006783982430

3. Nerem RM, Seliktar D. Vascular tissue engineering. Annu Rev Biomed Eng 2001; 3: 22543. doi:10.1146/annurev.bioeng.3.1.225

4. Jeong SI, Kim SH, Kim YH, Jung Y, Kwon JH, Kim BS. Manufacture of elastic biodegradable PLCL scaffolds for mechano-active vascular tissue engineering. J Biomater Sci Polym Ed 2004; 15: 64560. doi:10.1163/156856204323046906

5. Williamson MR, Black R, Kielty C. PCL-PU composite vascular scaffold production for vascular tissue engineering: Attachment, proliferation and bioactivity of human vascular endothelial cells. Biomaterials 2006; 27: 3608-16.

6. Patel HJ, Su SH, Patterson C, Nguyen KT. A combined strategy to reduce restenosis for vascular tissue engineering applications. Biotechnol Prog 2006; 22: 3844. doi:10.1021/bp050135e

7. Higgins SP, Solan AK, Niklason LE. Effects of polyglycolic acid on porcine smooth muscle cell growthand differentiation. J Biomed Mater Res 2003; 67A: 295302. doi:10.1002/jbm.a.10599

8. Zhu CH, Fan DD, Duan ZZ, Xue WJ, Shang LA, Chen FL. Initial investigation of novel human-like collagen/chitosan scaffold for vascular tissue engineering. $J$ Biomed Mater Res A 2009; 89A: 829-40. doi:10.1002/jbm.a.32256

9. Zorlutuna P, Hasirci N, Hasirci V. Nanopatterned collagen tubes for vascular tissue engineering. J Tissue Eng Regen Med 2008; 2: 373-7. doi:10.1002/term.99

10. Shaikh FM, Brien TPO, Callanan A, Kavanagh EG, Burke PE, Grace PA. Fibrin gel scaffold optimization for tissue engineering vascular grafts. Tissue Eng 2007; 13: 186.

11. Shaikh FM, Callanan A, Kavanagh EG, Burke PE, Grace PA, McGloughlin TM. Fibrin: A natural biodegradable scaffold in vascular tissue engineering. Cells Tissues Organs 2008; 188: 333-46. doi:10.1159/000139772

12. Yao L, Swartz DD, Gugino SF, Russell JA, Andreadis ST. Fibrin-based tissue-engineered blood vessels: Differential effects of biomaterial and culture parameters on mechani- cal strength and vascular reactivity. Tissue Eng 2005; 11: 991-1003. doi:10.1089/ten.2005.11.991

13. L'Heureux N, Paquet S, Labbe R, Germain L, Auger FA. A completely biological tissue-engineered human blood vessel. Faseb J 1998; 12: 47-56.

14. Boland ED, Matthews JA, Pawlowski KJ, Simpson DG, Wnek GE, Bowlin GL. Electrospinning collagen and elastin: Preliminary vascular tissue engineering. Front Biosci 2004; 9: 1422-32. doi:10.2741/1313

15. Yoo JJ, Liu J, Soker S, Komura M, Lim G, Atala A. Electrospinning fabrication of collagen-based scaffolds for vascular tissue engineering. Faseb J 2006; 20: A1101-A.

16. Huang ZM, Zhang YZ, Kotaki M, Ramakrishna S. A review on polymer nanofibers by electrospinning and their applications in nanocomposites. Compos Sci Technol 2003; 63: 2223-53. doi:10.1016/S0266-3538(03)00178-7

17. Ma PX. Biomimetic materials for tissue engineering. $A d v$ Drug Deliv Rev 2008; 60: 184-98.

18. He CL, Huang ZM, Han XJ. Fabrication of drug-loaded electrospun aligned fibrous threads for suture applications. $J$ Biomed Mater Res 2009; 89A: 8095. doi:10.1002/jbm.a.32004

19. Xu CY, Inai R, Kotaki M, Ramakrishna S. Aligned biodegradable nanotibrous structure: a potential scaffold for blood vessel engineering. Biomaterials 2004; 25: 87786. doi:10.1016/S0142-9612(03)00593-3

20. Stephens JS, Fahnestock SR, Farmer RS, Kiick KL, Chase DB, Rabolt JF. Effects of electrospinning and solution casting protocols on the secondary structure of a genetically engineered dragline spider silk analogue investigated via fourier transform Raman spectroscopy. Biomacromolecules 2005; 6: 1405-13. doi:10.1021/bm04 9296h

21. Zhou SB, Peng HS, Yu XJ, Zheng XT, Cui WG, Zhang ZR, et al. Preparation and characterization of a novel electrospun spider silk fibroin/poly(D,L-lactide) composite fiber. $J$ Phys Chem B 2008; 112: 11209-16. doi:10.1021/jp800913k

22. Zarkoob S, Eby RK, Reneker DH, Hudson SD, Ertley D, Adams WW. Structure and morphology of electrospun silk nanofibers. Polymer 2004; 45: 39737. doi:10.1016/j.polymer.2003.10.102

23. Huang ZM, Zhang YZ, Ramakrishna S, Lim CT. Electrospinning and mechanical characterization of gelatin nanofibers. Polymer 2004; 45: 53618. doi:10.1016/j.polymer.2004.04.005

24. Work R, Young C. The amino acid compositions of major and minor ampullate silks of certain orb-web-building spiders (Araneae, Araneidae). J Arachnol 1987: 65-80.

25. Walrafen G, Chu Y. Nature of collagen-water hydration forces: A problem in water structure. Chem Phys 2000; 258: 427-46. doi:10.1016/S0301-0104(00)00072-0

26. Sirichaisit J, Brookes V, Young R, Vollrath F. Analysis of structure/property relationships in silkworm (Bombyx mori) and spider dragline (Nephila edulis) silks using Raman spectroscopy. Biomacromolecules 2003; 4: $387-$ 94. doi:10.1021/bm0256956 
27. Zong X, Kim K, Fang D, Ran S, Hsiao B, Chu B. Structure and process relationship of electrospun bioabsorbable nanofiber membranes. Polymer 2002; 43: 440312. doi:10.1016/S0032-3861(02)00275-6

28. Tamada Y, Ikada Y. Fibroblast growth on polymer surfaces and biosynthesis of collagen. J Biomed Mater Res 1994; 28 : 783-90. doi:10.1002/jbm.820280705

29. Dee KC, Puleo DA, Bizios R. Blood-Biomaterial Interactions and Coagulation. An introduction to tissue"Cbiomaterial interactions, Wiley, New York. 2002: 37"C87.

Received 10 November, 2009; accepted 6 December, 2009; published online 9 December, 2009.

Copyright: (c) 2009 C. He et al. This is an open-access article distributed under the terms of the Creative Commons Attribution License, which permits unrestricted use, distribution, and reproduction in any medium, provided the original author and source are credited. 